\title{
ALDEHYDE EMISSIONS FROM A STATIONARY DIESEL ENGINE OPERATING WITH CASTOR OIL BIODIESEL - DIESEL OIL BLENDS
}

\begin{abstract}
P. B. Zarante, ABSTRACT
M. J. Da Silva,

O. S. Valente,

and J. R. Sodré

Pontifícia Universidade Católica de Minas

Gerais

Departamento de Engenharia Mecânica

Av. Dom José Gaspar, 500

The presence of aldehyde in the exhaust gas of a stationary, direct injection, compression ignition engine operating with castor oil biodiesel/diesel oil blends (B5, B10, B20 and B35) is analyzed. The diesel engine was operated with constant speed of $1800 \mathrm{rev} / \mathrm{min}$ and load of $37.5 \mathrm{~kW}$. The gas sample was collected directly from the exhaust. Aldehydes were identified and quantified using gas chromatography (GC) with flame ionization detector analyzer (FID). Acetaldehyde presented higher exhaust concentration than formaldehyde for all fuel blends tested. In general, the exhaust aldehyde levels were very low and did not present significant differences between the fuel blends tested.
\end{abstract}

CP. 30535-901, Belo Horizonte, MG, Brasil

paolabarros@hotmail.com

marcio@pucminas.br

osmano.valente@gmail.com

ricardo@pucminas.br
Keywords: Aldehydes, diesel engine, gas chromatography.

\section{NOMENCLATURE}

CC Carboxylic compound

$\mathrm{CH}_{2} \mathrm{O}$ Formaldehyde

$\mathrm{C}_{2} \mathrm{H}_{4} \mathrm{O}$ Acetaldehyde

DNPH 2,4-dinitrophenilhydrazine

EGR Exhaust gas recirculation

ES Electrospray

ESI eletrospray ionization

FID Flame Ionization Detector

FTIR Fourier transformed infra-red spectroscopy

GC Gas Chromatography

HC Hydrocarbons

HCO Aldehydes

HPLC High Performance Liquid Chromatography

$\mathrm{NO}_{\mathrm{X}} \quad$ Oxides of Nitrogen

MS Mass spectrometry

PM Particulate mass

UV Ultraviolet photo-oxidation

\section{INTRODUCTION}

Aldehydes (HCO) are non-regulated pollutants, but cause harmful effects to humans. Aldehydes can participate of complex reactions in the atmosphere, generating other gaseous oxidants such as ozone, which causes respiratory problems. In Brazil, the legislation only limits the emissions of formaldehyde $\left(\mathrm{CH}_{2} \mathrm{O}\right)$ and acetaldehyde $\left(\mathrm{C}_{2} \mathrm{H}_{4} \mathrm{O}\right)$ from vehicles equipped with spark ignition engines, as ethanol is largely used as fuel and it is known to be a potential aldehyde source. Although the legislation does not consider diesel engines, it is necessary to further investigate aldehyde emissions from diesel vehicles, especially after the introduction of biodiesel to diesel oil.

At present, Brazilian diesel fuel is constituted by a blend of $5 \%$ of biodiesel in diesel oil. The standard method to measure exhaust aldehydes is High Performance Liquid Chromatography (HPLC). In this work gas chromatography (GC) is used as an alternative method for aldehyde analysis to investigate its exhaust emission levels from a stationary diesel engine fuelled by castor oil biodiesel-diesel oil blends.

\section{LITERATURE REVIEW}

\section{Methods of aldehyde analysis}

Swarin et al. (1992) studied analytical methods based on the use of 2,4-dinitrophenilhydrazine (DNPH) as derivation reagent for collection and subsequent analysis of aldehydes and ketones by HPLC. The authors verified that formaldehyde does not produce a satisfactory reply to flame ionization detector (FID), but the remaining aldehydes, such as acetaldehyde and benzaldehyde, and ketones could be analyzed by GC if the concentration in the sample is big enough. Kataoka et al. (1998) demonstrated that aromatic and aliphatic, saturated and not saturated aldehydes can accurately be determined by GC with flame photometric detector. Christensen et al. (2001) measured formaldehyde and acetaldehyde using Fourier transformed infra-red spectroscopy (FTIR). An analytical method that uses high performance 
liquid chromatography and ultraviolet photooxidation with electrospray mass spectrometry (HPLC/UV/ES/MS) was developed as an analytical tool for carboxylic acid and aldehydes identification. Beyond the differentiation, eletrospray ionization with mass spectrometry (ESI/MS) could identify low concentration species, but, for longer retention times, the concentrations of some species are very low for the ultraviolet (UV) detector. Lewis et al. (2005) presented a new analytical method using liquid chromatography with ultraviolet eletrospray ionization mass spectrometry (LC-ESI-MS-UV), which was developed to analyze long chains of aldehydes and carboxylic acid. Zárante (2008) concluded that GC is an interesting alternative to the conventional HPLC method to determine aldehydes qualitatively and quantitatively in the exhaust of internal combustion engines

Roy (2008) introduced a new method of gas sampling for aldehyde analysis by HPLC, called bag sampling, which was used instead of the trapping gas sampling method. The superiority of the bag sampling method was claimed to be its transient gas checking capability. Guarieiro et al. (2008) compared the two most widely used carboxylic compounds (CC) collection methods: C18 cartridges coated with an acid solution of 2,4dinitrophenylhydrazine (2,4-DNPH) and impinger bottles filled in 2,4-DNPH solution. The impinger system was able to collect CC more efficiently and with lower error than the C18 cartridge system. Furthermore, propionaldehyde was nearly not sampled by $\mathrm{C} 18$ system at all. A new method for aldehyde analysis in the exhaust of internal combustion engines is developed by. The method uses gas chromatography with flame ionization detector, with the gaseous sample collected directly of the exhaustion collector. Formaldehyde and acetaldehyde had been identified and quantified for a 1,4 liters spark ignition production engine, fed with hydrate ethanol. The formaldehyde and acetaldehyde retention times had been consistent for all tested conditions. The results demonstrate that gas chromatography method is.

\section{Aldehyde emissions from diesel oil and biodiesel mixtures}

Graboski et al. (2003) evidenced that more than $75 \%$ of exhaust aldehydes from a diesel fuelled engine was composed by formaldehyde and acetaldehyde. No significant difference was found between aldehyde emissions from biodiesel of different origins and diesel oil. Sluder et al. (2004) verified that aldehyde emissions from a diesel engine are initially reduced with the increase of exhaust gas recirculation (EGR) and they are increased for low oxides of nitrogen $\left(\mathrm{NO}_{\mathrm{X}}\right)$ and low particulate matter
(PM) combustion regime, especially formaldehyde and acetaldehyde, but also benzaldehyde, propionaldehyde and acrolein. High aldehyde emissions are consistent with low-temperature combustion regimes. Abrantes et al. (2005) verified that formaldehyde/acetaldehyde emissions ratio from light commercial diesel vehicles is constant around $74 \% / 26 \%$. Aldehyde emissions from diesel vehicles were significant lower when compared with spark ignition vehicles.

Corrêa and Arbilla (2007) observed that CC emissions from a heavy duty diesel engine showed different behavior when biodiesel-diesel oil mixtures were used instead of diesel oil. Benzaldehyde showed reduced emission, but all the remaining carbonyl compounds showed significant increase: $2.6 \%$ to $35.5 \%$ for formaldehyde; $1.4 \%$ to $15.8 \%$ for acetaldehyde; $2.1 \%$ to $22.0 \%$ for acroleine + acetone; $0.8 \%$ to $10.0 \%$ for propionaldehyde; and $3.3 \%$ to $26.0 \%$ for butyraldehyde. The dominant exhaust aldehyde components from engines fuelled by biodiesel-diesel oil blends are formaldehyde and acetaldehyde, accounting for over $75 \%$ of total aldehyde emissions (Peng et al., 2008). He et al. (2009) noticed that the use o soybean biodiesel multiplied by almost three times $\mathrm{CC}$ emissions in comparison with diesel oil, and contribute to increase total hydrocarbon (HC) emissions. Formaldehyde is the most abundant CC emitted from both, biodiesel and diesel oil, participating with $46.2 \%$ and $62.7 \%$ respectively, followed by acetaldehyde, acroleine and acetone. The experimental results by Yuan et al. (2009) indicated that formaldehyde is the main exhaust $\mathrm{CC}$ from a heavy duty diesel engine fuelled by palm biodiesel-diesel oil blends following a European transient cycle, contributing with 70.1\%$76.2 \%$ of the total carbonyl concentration. Close numbers have been found by Lin et al. (2009). Of more than 150 organic species, the largest portion of exhaust emissions from a diesel engine is consisted of formaldehyde, acetaldehyde, and naphthalene and its derivatives, which are significantly reduced with the use of EGR system, crankcase emissions coalescer, and diesel particulate filter (Liu et al., 2009).

\section{EXPERIMENTS}

The general characteristics of the diesel engine and the power generator used in the experiments are shown in Tabs. 1 and 2. The generator electric load was supplied by a $50 \mathrm{~kW}$ bank of electric resistances. The resistances were grouped in seven modules, being two of $2.5 \mathrm{~kW}$, one of $5 \mathrm{~kW}$, and four of 10 $\mathrm{kW}$, allowing for load increments $2.5 \mathrm{~kW}$. The tests were performed with the diesel engine operating at $1800 \mathrm{rev} / \mathrm{min}$ crankshaft speed, with load of $37.5 \mathrm{~kW}$. The engine was fuelled with diesel oil (B0) and fuel 
blends containing 5\% (B5), 10\% (B10), 20\% (B20), and $35 \%$ (B35) of castor oil biodiesel in diesel oil.

Table 1. Diesel engine details.

\begin{tabular}{ll}
\hline PARAMETER & TYPE OR VALUE \\
\hline Manufacturer & MWM \\
\hline Model & D229-4 \\
\hline Serial Number & B1N426219 \\
\hline Construction Type & 4 strokes, in line \\
\hline Injection Time & Direct \\
\hline Diâmeter x stroke & $102 \times 120 \mathrm{~mm}$ \\
\hline Cylinder number & 4 \\
\hline Piston displacement & 0.980 liters \\
\hline Total piston displacement & 3.922 liters \\
\hline Aspiration & Natural \\
\hline Rotation & $1800 \mathrm{rpm}$ \\
\hline Power & $44 \mathrm{~kW}(60 \mathrm{hp})$ \\
\hline
\end{tabular}

Table 2. Power generator details

\begin{tabular}{ll}
\hline PARAMETER & TYPE OR VALUE \\
\hline Manufacturer & GRAMACO \\
\hline Model & G2R \\
\hline Power & $50 \mathrm{kVA}$ \\
\hline Regimen & S1 (continuous) \\
\hline Phases number & 3 \\
\hline Pole number & 4 \\
\hline Speed & $1800 \mathrm{rpm}$ \\
\hline Tension & $220 \mathrm{~V}$ \\
\hline Frequency & $60 \mathrm{~Hz}$ \\
\hline Current & $132 \mathrm{~A}$ \\
\hline Power factor & 0.80 \\
\hline
\end{tabular}

An Agilent 6850 GC model gas chromatograph was used for formaldehyde and acetaldehyde analysis. The sample was collected directly from the exhaust pipe and directed into the chromatograph. The chromatograph parameters for aldehyde determination were modified from base values obtained from the equipment manufacturer, to optimize the analysis. A capillary, non-polar, chromatograph column composed by stationary phase of poly-dimethyl siloxane (DB-1), with -60 to $350^{\circ} \mathrm{C}$ temperature range, was used in the analysis. The chromatograph oven temperature was adjusted in a preliminary analysis, in order to get a good separation of the components analyzed. The chromatograph response was stored in a microcomputer through a program, including date, peak retention times, peak areas and peak type, allowing for the calculation of the component concentration. The chromatograph was calibrated for aldehydes and hydrocarbon analysis through chromatograms supplied by the manufacturer at the same operating condition of the equipment. The carrier gas used was helium, hydrogen was used as fuel for the FID detector, and nitrogen was used as make up gas, all with $99.99 \%$ degree of purity. Tab. 3 describes the adjusted method in the present work.

Table 3. GC program adjustment for formaldehyde and acetaldehyde analysis.

\begin{tabular}{ll}
\hline PARAMETER & SPECIFICATION \\
\hline Carrier gas & Helium \\
\hline Carrier gas speed & $36 \mathrm{~cm} / \mathrm{s} @ 35^{\circ} \mathrm{C}$ \\
\hline Oven temperature & $35^{\circ} \mathrm{C} / 40^{\circ} \mathrm{C}$ isothermal \\
\hline Injector division reason & $1: 100$ \\
\hline Injector temperature & $300^{\circ} \mathrm{C}$ \\
\hline Detector & $\mathrm{FID}$ \\
\hline Detector temperature & $200^{\circ} \mathrm{C}$ \\
\hline Composition gas & Nitrogênio \\
\hline Gas composition flow & $30 \mathrm{ml} / \mathrm{min}$ \\
\hline
\end{tabular}

\section{RESULTS and DISCUSSION}

In the Figs. 1 to 5 it is observed the chromatographic analysis of the exhaust gas from the diesel engine fuelled by diesel oil and mixtures of diesel oil /biodiesel (B5, B10, B20, B35) at $37.5 \mathrm{~kW}$ and $1800 \mathrm{rev} / \mathrm{min}$ At this operating condition exhaust aldehyde concentration was observed to be the highest for the engine studied. Formaldehyde was identified just as a trace for all fuel blends, as it was below the detection level of the equipment. Acetaldehyde was below the detection level for B5 and B20 blends, but it was adequately identified for diesel oil and B35 fuel blend. Both formaldehyde and acetaldehyde retention times were consistent with the values supplied by the equipment manufacturer. Methane peak in the exhaust gas analysis appeared late in comparison with the retention time obtained for methane in pure air, which was previously analyzed using a standard gas mixture.

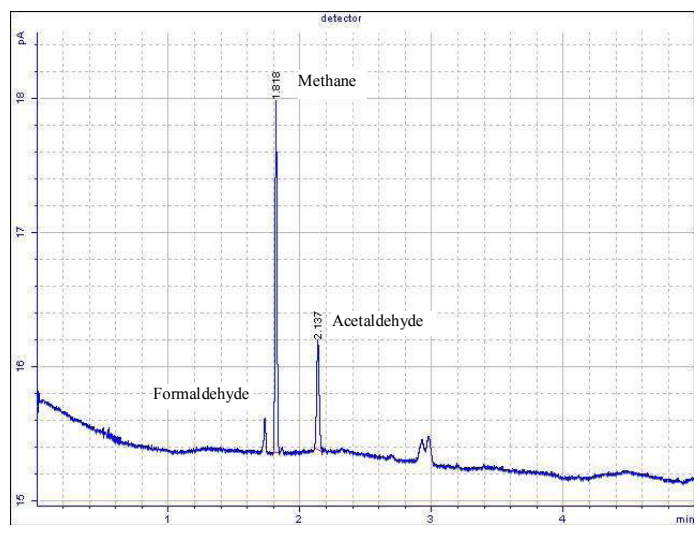

Figure 1. Chromatogram of exhaust aldehydes and methane. Fuel: diesel oil, load: 37.5 kW, speed: 1800 $\mathrm{rev} / \mathrm{min}$, column: poly-dimethyl-siloxane. 


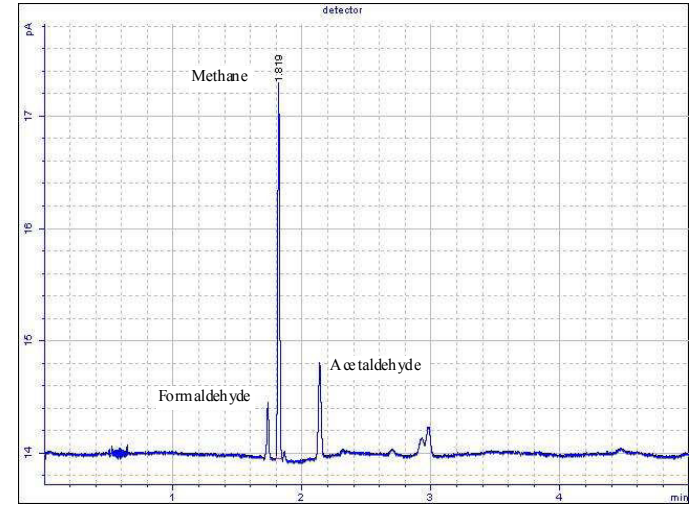

Figure 2. Chromatogram of exhaust aldehydes and methane. Fuel: B5, load: 37.5 kW, speed: 1800 rev/min, column: poly-dimethyl-siloxane.

Tab. 4 shows the acetaldehyde concentrations obtained from the chromatograms for the tests with diesel oil, B10 and B35 blends (Figs. 1, 3 and 5). The results are the average of three tests performed for each fuel at the operating condition described. There is not a significant difference between the acetaldehyde concentration produced by diesel oil in comparison with the biodiesel blends tested, although it is noticed a slight reduction of acetaldehyde concentration with biodiesel concentration in the blend. This trend is probably due to the higher viscosity of castor oil biodiesel in comparison with diesel oil (Valente et al., 2011), which increases the fuel amount injected (Valente et al., 2010) and, thus, decreases combustion temperature as a result of fuel evaporation. As mentioned by Sluder et al. (2004), lower combustion temperatures produces higher aldehyde concentrations. Overall, for all fuels, aldehyde concentration in diesel engine exhaust is very low, agreeing with the findings by Corrêa and Arbilla (2007), Peng et al. (2008), He et al. (2009), Yuan et al. (2009), and Lin et al. (2009).

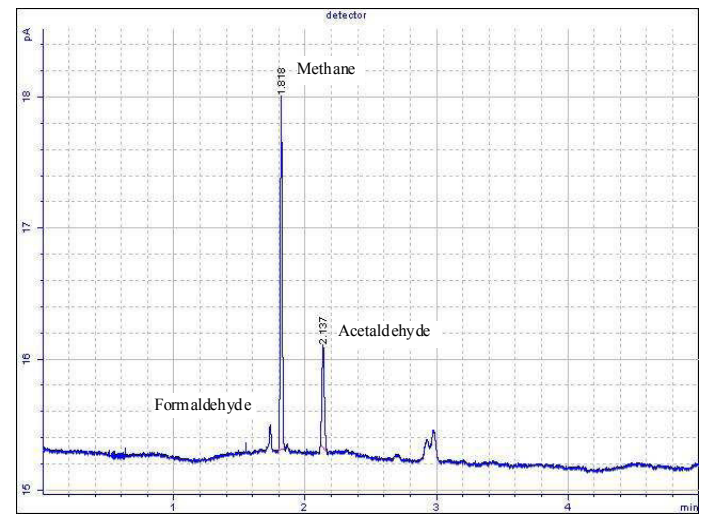

Figure 3. Chromatogram of exhaust aldehydes and methane. Fuel: B10, load: 37.5 kW, speed: 1800 $\mathrm{rev} / \mathrm{min}$, column: poly-dimethyl-siloxane.

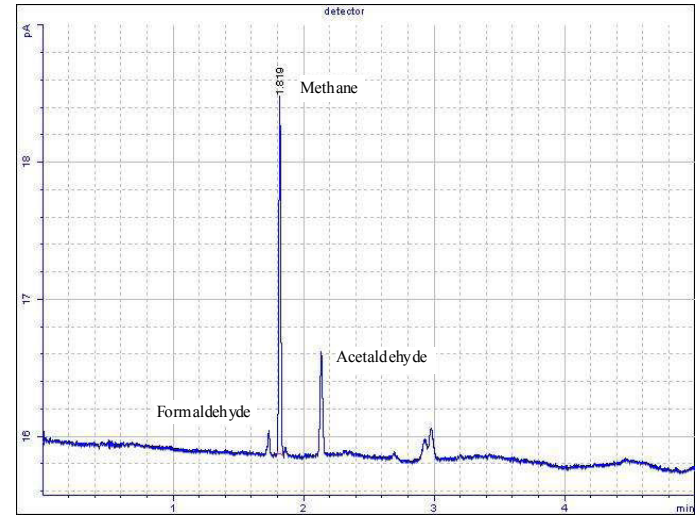

Figure 4. Chromatogram of exhaust aldehydes and methane. Fuel: B20, load: 37.5 kW, speed: 1800 $\mathrm{rev} / \mathrm{min}$, column: poly-dimethyl-siloxane.

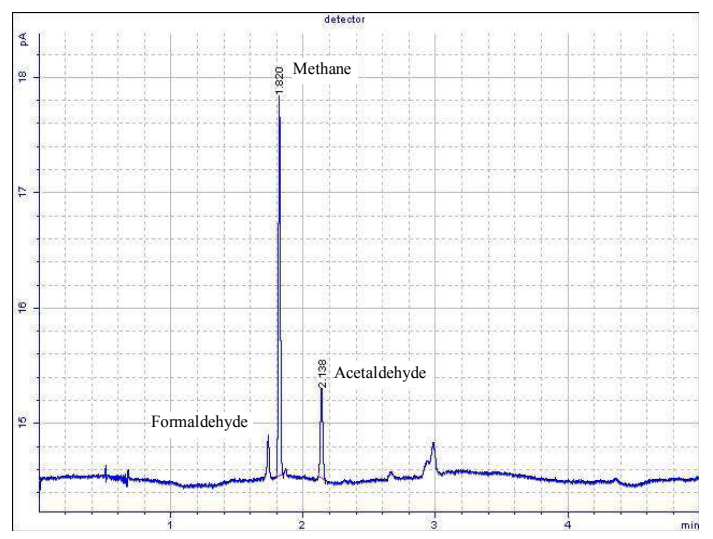

Figure 5. Chromatogram of exhaust aldehydes and methane. Fuel: B35, load: 37.5 kW, speed: 1800 rev/min, column: poly-dimethyl-siloxane.

Table 4. Exhaust acetaldehyde concentration evaluated from chromatograms for diesel oil, B10 and B35.

\begin{tabular}{ll}
\hline FUEL & CONCENTRATION (ppm) \\
\hline Diesel oil & 84.87 \\
\hline B10 & 84.46 \\
\hline B35 & 81.45 \\
\hline
\end{tabular}

\section{CONCLUSIONS}

Gas chromatography has proved to be an useful tool for engine exhaust aldehyde measurement, but it requires high sample amounts to perform an adequate analysis. Detectable amounts of aldehydes were obtained just with high engine load. Overall, aldehyde concentration from a diesel engine fuelled by diesel oil or castor oil biodiesel/diesel oil blendes is very low. Acetaldehyde is the aldehyde with higher 
concentration present in diesel engine exhaust. Only traces of formaldehyde were detected for all fuels tested. No remarkable difference was found between the aldehyde levels produced by diesel oil and castor oil biodiesel/diesel oil blends.

\section{REFERENCES}

Abrantes R., Assunção, J. and Hiraia, E., 2005, Caracterização das Emissões de Aldeídos de Veículos do Ciclo Diesel, Revista da Saúde Pública, Vol. 39, No 3, pp. 479-485.

Christensen, M., Johansson, B. and Hultqvist, A., 2001, The Effect of Piston Topland Geometry on Emissions of Unburned Hydrocarbons from a Homogeneous Charge Compression Ignition (HCCI) Engine, SAE International Spring Fuels \& Lubricants Meeting and Exposition, SAE Paper 2001-01-1893, Orlando, FL, USA.

Corrêa, S. and Arbilla, G., 2007, Carbonyl Emissions in Diesel and Biodiesel Exhaust, Atmospheric Environment, Vol. 42, pp. 769-775

Graboski, M. S., McCormick, R. L., Alleman, T.L. and Herring, A. M., 2003, The Effect of Biodiesel Composition on Engine Emissions from a DDC Series 60 Diesel Engine, National Renewable Energy Laboratory, NREL/SR-510-31461, USA.

Guarieiro, L., Pereira, P., Torres, E., Da Rocha, G., and De Andrade, J., 2008, Carbonyl Compounds Emitted by a Diesel Engine Fuelled with Diesel and Biodiesel-diesel Blends: Sampling Optimization and Emissions Profile, Atmospheric Enviroment, Vol. 42, pp. 8211-8218.

He, C., Yunshan, G., Jianwei, T., Kewei, Y., Xunkun, H., Junfang, W. and Asad, S., 2009, Comparison of Carbonyl Compounds Emissions from Diesel Engine Fueled with Biodiesel and Diesel, Atmospheric Environment, Vol. 43, pp. 3657-3661.

Kataoka, H., Kondo, T. and Sumida, A., 1998, Gas Chromatographic Determination of Aldehydes in Combustion Smoke Samples, Analytica Chimica Acta, Vol. 358, No. 3, pp. 269-275.

Lewis, S.A., Storey, J. M. E., Bunting, B. and Szybist, J. P., 2005, Partial Oxidation Products and other Hydrocarbon Species in Diesel HCCI Exhaust, Powertrain \& Fluid Systems Conference \& Exhibition, SAE Paper 2005-01-3737, San Antonio, TX, USA.

Lin, Y-Ch., Wu, T-Y., Ou-Yang, W-Ch. and Chen, Ch-B., 2009, Reducing Emissions of Carbonyl Compounds and Regulated Harmful Matters from a Heavy-Duty Diesel Engine Fueled with Paraffinic/Biodiesel Blends at One Low Load SteadyState Condition, Atmospheric Environment, Vol. 43, No. 16, pp. 2642-2647.

Liu, G., Berg, D., Vasys, V., Dettman, M., Zielinska, B. and Schauer, J., 2009, Analysis of C1, C2, through C33 Particle-Phase and Semi-Volatile Organic Compound Emissions from Heavy-Duty
Diesel Engines, Atmospheric Environment, Vol. 44, pp. 1108-1115.

Peng, Ch-Y., Yang, H-H., Lan, Ch-H., Chien Sh-M. and Shu-Mei., 2008, Effects of the Biodiesel Blend Fuel on Aldehyde Emissions from Diesel Engine Exhaust, Atmospheric Environment, Vol. 42, No. 5, pp. 906-915.

Roy, M., 2008, HPLC Analysis of Aldehydes in Automobile Exhaust Gas: Comparison of Exhaust Odor and Irritation in Different Types of Gasoline and Diesel Engines, Energy Conversion and Management, Vol. 49, N. 5, pp. 1111-1118.

Sluder, C. S., Wagner, R. M., Lewis, S. A. and Storey, J. M. E., 2004, Exhaust Chemistry of LowNOx, Low-PM Diesel Combustion, SAE 2004 World Congress \& Exhibition, SAE Paper 2004-01-0114, Detroit, MI, USA.

Swarin, S. J., Loo, J. F., Chladek, E., Drouillard, M. S. and Tejada, S. B., 1992, Advanced Emissions Speciation Methodologies for the Auto/Oil Air Quality Improvement Research Program - II. Aldehydes, Ketones and Alcohols, SAE Technical Paper Series, SAE Paper 920321, Warrendale, PA, USA.

Valente, O. S., Silva, M. J., Pasa, V. M. D., Belchior, C. R. P. and Sodré, J. R., 2010, Fuel Consumption and Emissions from a Diesel Power Generator Fuelled with Castor Oil and Soybean Biodiesel, Fuel, Vol. 89, pp. 3637-3642.

Valente, O. S., Silva, M. J., Pasa, V. M. D., Belchior, C. R. P. and Sodré, J. R., 2011, PhysicalChemical Properties of Waste Cooking Oil Biodiesel and Castor Oil Biodiesel Blends, Fuel, Vol. 90, p.1 3.

Yuan, Ch., Lin, Y-Ch., Tsai, Ch-H., Wu, ChCh., and Lin, Y-Sh., 2009, Reducing Carbonyl Emissions from a Heavy-Duty Diesel Engine at US Transient Cycle Test by Use of Paraffinic/Biodiesel Blends, Atmospheric Environment, Vol. 43, No. 39, pp. 6175-6181.

Zárante, P., Albuquerque, P., Costa, and T., Sodré, J.R., 2008, Medição de Aldeídos na Exaustão Usando Cromatografia a Gás, SAE BRASIL 2008 XVII International Mobility Technology Conference and Exhibit, SAE Technical Paper Series 2008-360036, São Paulo, SP.

Received: January 14, 2010

Revised: February 14, 2010

Accepted: March 14, 2010 